\title{
Holmium Laser Assisted foam Sclerotherapy (LAFOS): a new Development of Sclerotherapy for Insufficient Saphenous Veins
}

Gachet G. ${ }^{1}$

${ }^{1}$ França.

E-mail: giga1@orange.fr

Gachet, G. 2013. Holmium Laser Assisted foam Sclerotherapy (LAFOS): a new Development of Sclerotherapy for Insufficient Saphenous Veins, p.55. In: Bastos, Francisco Reis. Anais do V Simpósio Internacional de Flebologia [Blucher Medical Proceedings n.1 v.1]. São Paulo: Blucher, 2014

http://dx.doi.org/10.5151/medpro-flebo-SIF_32
Foam sclerotherapy has represented a true revolution in the treatment of venous chronic disease as the dramatic enhancement in occlusion rate of saphenous veins has now changed the need for more invasive procedure.

In many countries surgery or thermal ablation has been replaced by foam sclerotherapy in the treatment of $<7 \mathrm{~mm}$ incompetent saphenous veins.

For larger veins the immediate and late results of foam sclerotherapy are still debatable. We have developed a new treatment where a special holmium laser with uniques properties is coupled to foam sclerotherapy (L.A.FO.S. or laser assisted foam sclerotherapy). This permits a venous shrinkage of the target vein immediately before foam injection. Uniques properties of this laser make possible to perform this treatment without anesthesia as an office procedure. In fact while the tunica media is shrinked, both endothelium and adventitia are not affected by laser as their temperature do not rise over $43^{\circ}$.

The treatment is performed with the insertion of a short catheter which allows both fiber insertion and subsequent foam injection.

We are presenting the results of the first 50 cases of LAFOS. From original paper from Frullini A, Fortuna D - Studio Medico flebologico Figline Valdarno - Florence - ITALY. E-mail: info@venevaricose.it

Kew-words: Sclerotherapy, laser, VCD, varices. 